\title{
ANALISIS KONDISI SANITASI LANTAI RUANG DAPUR TERHADAP JUMLAH ANGKA KUMAN DI RSUD ANDI MAKKASAU KOTA PAREPARE
}

\author{
Analysis of the Conditions of Kitchen Room Floor Sanitation Against the Number of \\ Germs in Andi Makkasau District Hospital in Parepare City
}

\author{
Dirman Sudarman, Ramlan, Abdul Madjid, Ishaq Nusu \\ (Program Studi Kesehatan Masyarakat Fakultas Ilmu Kesehatan Universitas Muhammadiyah \\ Parepare) (dirmansudarman@gmail.com)
}

\begin{abstract}
ABSTRAK
Jenis penelitian ini adalah quasi experimental dengan rancangan pretest dan postest. Tujuan penelitian ini adalah adalah unutuk mengetahui kondisi sanitasi lantai ruang dapur sebelum dan sesudah penambahan kadar desinfektan sebanyak $40 \mathrm{ml}, 30 \mathrm{ml}$, dan $20 \mathrm{ml} / 3$ liter air serta menghitung jumlah presentase penurunannya di lakukan 2 kali perhitungan pada setiap media dengan inkubasi selama 24-48 jam. Berdasarkan hasil yang di dapatkan dalam penelitian ini jumlah kuman sebelum penambahan desinfektan di ruang dapur tidak memenuhi syarat pada bagian input 1260-1284 $\mathrm{CFU} / \mathrm{cm}^{2}$, bagian proses $1175-1201 \mathrm{CFU} / \mathrm{cm}^{2}$, dan bagian output $825-857 \mathrm{CFU} / \mathrm{cm}^{2}$, tapi setelah penambahan kadar desinfektan $40 \mathrm{ml}$ pada ruang input jumlah 590-607 belum memenuhi syarat, 30 $\mathrm{ml}$ untuk ruang proses 554-583 $\mathrm{CFU} / \mathrm{cm}^{2}$ belum memnuhi syarat, dan $20 \mathrm{ml}$ untuk ruang output 412$435 \mathrm{CFU} / \mathrm{cm}^{2}$ sudah memenuhi syarat. Berdasarkan Keputusan Menteri kesehatan Republik Indonesia Nomor1204/Menkes/SK/X/2004 tentang Persyaratan kesehatan Lingkungn Rumah Sakit, Persyaratan angka kuman untuk lantai dapur untuk batas maksimum yaitu $500 \mathrm{CFU} / \mathrm{cm}^{2}$. Dimana kreteria di katakan menemuhi syarat apabila jumlah kuman di $<500 \mathrm{CFU} / \mathrm{cm}^{2}$ dan tidak memenuhi syarat apabila jumlah kuman $>500 \mathrm{CFU} / \mathrm{cm}^{2}$.
\end{abstract}

Kata kunci : Sanitasi, mikroorganisme, desinfektan

\begin{abstract}
This type of research is quasi experimental with pretest and posttest design. The purpose of this study was to find out the sanitation conditions of the kitchen room floor before and after the addition of disinfectant levels of $40 \mathrm{ml}, 30 \mathrm{ml}$, and $20 \mathrm{ml} / 3$ liters of water and calculate the amount of the percentage reduction done twice in each medium with incubation for 24-48 hours. Based on the results obtained in this study the number of germs before the addition of disinfectant in the kitchen room does not meet the requirements on the input section 1260-1284 CFU/ $\mathrm{cm}^{2}$, the process

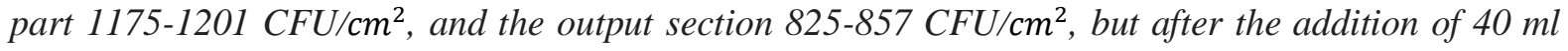


disinfectant in the input chamber the number of 590-607 has not met the requirements, $30 \mathrm{ml}$ for the process room 554-583 CFU/ $\mathrm{cm}^{2}$ has not fulfilled the requirements, and $20 \mathrm{ml}$ for the output room 412-435 CFU/ $/ \mathrm{cm}^{2}$ already meets the requirements. Based on the Decree of the Minister of Health of the Republic of Indonesia Number 1204 / Menkes / SK / X / 2004 concerning Hospital Environmental

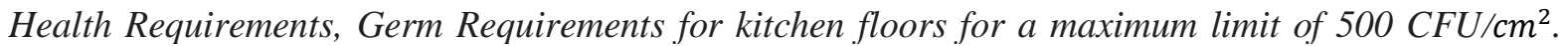
Where the criteria are said to meet the conditions for the number of germs at $<500 \mathrm{CFU} / \mathrm{cm}^{2}$ and do not meet the requirements if the number of germs $>500 \mathrm{CFU} / \mathrm{cm}^{2}$.

Keywords: Sanitation, microorganisms, disinfectants 


\section{PENDAHULUAN}

Pembangunan kesehatan bertujuan

untuk meningkatkan kesadaran,kemauan, dan kemampuan hidup sehat bagi setiap orang agar terwujud derajat kesehatan masyarakat yang setinggi-tingginya, sebagai investasi bagi pembangunan sumber daya manusia yang produktif secara sosial dan ekonomis. Penyebab penyakit dapat berada di lantai, udara, peralatan medis dan non medis. Rumah sakit selain untuk mencari kesembuhan, juga merupakan tempat bagi berbagai macam penyakit, yang berasal dari penderita maupun dari pengunjung yang berstatus karier. Kuman penyakit ini dapat hidup dan berkembang di lingkungan rumah sakit, seperti udara, air, lantai, makanan dan benda-benda peralatan medis maupun non medis

Rumah sakit sebagai tempat pelayanan kesehatan bagi masyarakat harus memiliki ruang dapur yang memenuhi syarat kesehatan, baik kualitas dan kebersihan lantai, konstruksinya maupun fasilitasnya. Didalam ruangan yang tidak memenuhi syarat kesehatan, penyakit dapat menular melalui peralatan, bahan-bahan yang digunakan, makanan dan minuman, petugas kesehatan, dan pengunjung. Untuk mencegah penularan penyakit, Menteri Kesehatan mensyaratkan agar lantai yang ada dalam ruang dapur harus bebas kuman patogen dengan angka total kuman tidak lebih dari $500 \mathrm{CFU} / \mathrm{cm}^{2}{ }^{1}{ }^{1}$

Pengepelan menggunakan desinfektan adalah usaha untuk membersihkan lantai dengan cara kimiawi untuk mengurangi dan menghilangkan mikroorganisme patogen penyebab penyakit. Dalam hal ini yang perlu diperhatikan adalah desinfektan dan metode yang efektif sehingga dapat tercapai daya bunuh yang optimal pada kuman. Bahan kimia yang digunakan untuk mencegah terjadinya infeksi atau pencemaran jasad renik, dan untuk membunuh atau menurunkan jumlah mikroorganisme disebut desinfektan. Efektifitas dari desinfektan terhadap kuman pada lantai kadang -kadang tidak tercapai meskipun sudah diuji di laboratorium dengan baik. Efektifitas desinfektan dapat diuji langsung dengan cara setelah lantai di beri bahan desinfektan kemudian di hitung jumlah jasad reniknya yang ada di lantai tersebut. Faktor utama yang menentukan bagaimana desinfektan bekerja adalah kadar desinfektan, waktu yang telah diberikan kepada desinfektan untuk bekerja, suhu desinfektan, jumlah dan tipe mikroorganisme yang ada serta keadaan ruangan yang di desinfeksi. ${ }^{2}$

RSUD Andi Makkasau Parepare merupakan salah satu rumah sakit milik pemerintah kota yaitu kota parepare yang tergolong dalam rumah sakit kelas $\mathrm{B}$,rumah sakit ini telah teregistrasi semenjak 17/04/1998 dengan nomor surat izin 02546/yankes2/IV/2014 dan tanggal surat izin 08/04/2014 dari Dinas Provensi Sulawesi Selatan. RSUD Andi Makkasau Kota Parepare mempunyai luas tanah $44.582 \mathrm{~cm}^{2}$ dengan luas bangunan kurang lebih $30.000 \mathrm{~cm}^{2}$. dengan jumlah tempat tidur dibagi dengan beberapa 
tipe dengan jumlah keseluruhan sekitar 244 kamar tidur,dengan jumlah pegawai sekitar 892 orang dengan berbagai macam bidang keahlian dan jumlah pengunjung yang banyak sehingga dapat menimbulkan lingkungan rumah sakit jadi tidak sehat seperti lantai menjadi kotor,banyak sampah dan permasalahan lainnya. lantai mempunyai kemungkinan lebih besar dalam kondisi kotor di bandingkan dengan dinding dan langit-langit ruangan.

Ruang dapur merupakan tempat untuk menyimpan, mengelola dan menyajikan berbagai macam sumber makanan dan minuman untuk pasein rawat inap.maka ruang dapur harus dalam keadaan bersih baik dari kotoran atau sampah yang kasat mata maupun bakteri atau kuman sesuai standar kesehatan tidak lebih dari $500 \mathrm{CFU} / \mathrm{cm}^{2}$.Petugas RSUD Andi Makkasau Kota Parepare melakukan pengepelan lantai ruang dapur setelah ruangan di bersihkan dengan cara menyapu dari ruangan paling ujung kemudian baru di lakukan pengepelan.pembersihan lantai di lakukan pada pagi hari mulai jam 08.00 - 10.00 dan siang pada pukul 14.00-16.00 dengan cara pembersihan yang sama juga dengan petugas yang sama.

Mikroorganisme

Patogen dan Penyakitnya menurut Nyoman Suendra, et. Al. (1993, h. 33), Mikroorganisme parasit dan yang menyebabkan penyakit pada manusia, merupakan jenis mikroorganisme pathogen seperti bakteri, virus, jamur, dan protozoa.Mikroorganisme selain ada yang bermanfaat dalam tubuh manusia yang sehat misalnya usus yang membentuk vitamin $\mathrm{K}$ dan membantu absorbsi makanan, ada juga yang merugikan manusia. Mikroorganismepathogen antara lain dapat menimbulkan penyakit pada saluran pencernaan, saluran pernapasan, dan saluran air seni. $^{3}$

\section{BAHAN DAN METODE}

Jenis penelitian ini adalah menggunakan quasi eksperimen, dengan maksud untuk mengukur jumlah angka kuman sebelum dan sesudah perlakuan penambahan kadar desinfektan pada lantai ruang dapur di RSUD Andi Makkasau Kota Parepare. Dengan rancangan yang di gunakan adalah pretest (pengukuran jumlah angka kuman pada lantai ruang dapur RSUD Andi Makkasau Kota Parepare sebelum penambahan desinfektan) dan postest (pengukuran jumlah angka kuman pada lantai ruang dapur RSUD Andi Makkasau Kota Parepare setelah penambahan desinfektan). Populasi pada penelitian ini adalah kuman lantai ruang dapur di RSUD Andi Makkasau Kota Parepare dan Sampel yang digunakan adalah lantai ruang dapur dengan 3 titik perlakuan Metode pengambilan sampel yang digunakan adalah metode purposive sampling, artinya teknik pengambilan sesuai dengan kehendak peneliti sesuai dengan tujuan penelitian.

Data yang diperoleh berdasarkan hasil laboratorium UPTD Laboratorium Dinas Lingkungan Hidup Kota Parepare jumlah 
angka kuman pada ruang dapur RSU Andi Makkasau Kota Parepare sebelum dan sesudah perlakuan penambahan desinfektan. Percobaan dilakukan dengan dua kali perhitungan, dari hasil percobaan dilakukan perbandingan jumlah angka kuman sebelum dan sesudah perlakuan penambahan desinfektan sebanyak $40 \mathrm{ml}, 30 \mathrm{ml}$, dan $20 \mathrm{ml}$ dalam setiap 3 liter air.

\section{HASIL}

Pengukuran Angka Kuman Lantai Ruang Dapur di RSUD Andi Makkasau Kota Parepare di Ruang Input(Bagian Penyimpanan) dengan waktu 15 menit pada inkubasi 24-48 jam pada Tabel 1. Menungjukkan bahwa angka kuman lantai ruang dapur di RSUD Andi Makkasau Kota Parepare di ruangan input(bagian penyimpanan). Di perhitungan pertama dengan lama inkubasi 24 jam jumlah kuman yang di hasilkan dengan pengukuran laboratorium dengan media petrifilm sebelum perlakuan sebanyak $1260 \mathrm{CFU} / \mathrm{cm}^{2}$, sedangkan jumlah kuman menjadi 590 $\mathrm{CFU} / \mathrm{cm}^{2}$ setelah perlakuan dengan pengepelan dengan penambahan desinfektan dengan kadar $40 \mathrm{ml}$. Pada perhitungan yang kedua dengan lama inkubasi 48 jam jumlah kuman baik itu sebelum perlakuan dan sesudah perlakuan dengan penambahan desinfektan sebanyak $40 \mathrm{ml}$ mengalami sedikit peningkatan, di sebelum perlakuan dengan jumlah $1260 \quad \mathrm{CFU} / \mathrm{cm}^{2}$ menjadi 1284 $\mathrm{CFU} / \mathrm{cm}^{2}$, jadi peningkatan jumlah coloni sekitar $24 \mathrm{CFU} / \mathrm{cm}^{2}$. Begitu juga dengan jumlah kuman setelah perlakuan mengalami peningkatan dari $590 \mathrm{CFU} / \mathrm{cm}^{2}$ menjadi 607 $\mathrm{CFU} / \mathrm{cm}^{2}$ ada juga peningkatan jumlah kuman sekitar $17 \mathrm{CFU} / \mathrm{cm}^{2}$. Jadi jumlah penurunan angka kuman sebelum dan sesudah perlakuan dengan penambahan desinfektan dengan kadar $40 \mathrm{ml}$ di ruang input( bagian penyimpanan) yaitu pada perhitungan pertama penurunan jumlah kuman sekitar $670 \mathrm{CFU} / \mathrm{cm}^{2}$ dan penurunan jumlah kuman pada perhitungan kedua sekitar $677 \mathrm{CFU} / \mathrm{cm}^{2}$.

Pengukuran angka kuman pada titik 2 lantai ruang dapur di RSUD Andi Makkasau Kota Parepare di ruang proses (bagian pengelolaan) dengan waktu 15 menit pada inkubasi 24-48 jam. Pada Tabel 2. menunjukkan bahwa angka kuman lantai ruang dapur di RSUD Andi Makkasau Kota Parepare di ruangan proses (bagian pengelolaan). Di perhitungan pertama dengan lama inkubasi 24 jam jumlah kuman yang di hasilkan dengan pengukuran laboratorium dengan media petrifilm sebelum perlakuan sebanyak $1175 \mathrm{CFU} / \mathrm{cm}^{2}$, sedangkan jumlah kuman menjadi $554 \mathrm{CFU} / \mathrm{cm}^{2}$. Setelah perlakuan dengan pengepelan dengan penambahan desinfektan dengan kadar $30 \mathrm{ml}$. Pada perhitungan yang kedua dengan lama inkubasi 48 jam jumlah kuman baik itu sebelum perlakuan dan sesudah perlakuan 
dengan penambahan desinfektan sebanyak 30 $\mathrm{ml}$ mengalami sedikit peningkatan, di sebelum perlakuan dengan jumlah $1175 \mathrm{CFU} / \mathrm{cm}^{2}$ menjadi $1201 \mathrm{CFU} / \mathrm{cm}^{2}$, jadi peningkatan jumlah coloni sekitar $26 \mathrm{CFU} / \mathrm{cm}^{2}$. Begitu juga dengan jumlah kuman setelah perlakuan mengalami peningkatan dari $554 \mathrm{CFU} / \mathrm{cm}^{2}$ menjadi $583 \mathrm{CFU} / \mathrm{cm}^{2}$. Ada juga peningkatan jumlah kuman sekitar $29 \mathrm{CFU} / \mathrm{cm}^{2}$. Jadi jumlah penurunan angka kuman sebelum dan sesudah perlakuan dengan penambahan desinfektan dengan kadar $30 \mathrm{ml}$ di ruang proses( bagian pengelolaan) yaitu pada perhitungan pertama penurunan jumlah kuman sekitar $621 \mathrm{CFU} / \mathrm{cm}^{2}$ dan penurunan jumlah kuman pada perhitungan kedua sekitar 618 $\mathrm{CFU} / \mathrm{cm}^{2}$.

Pengukuran Angka Kuman Lantai Ruang Dapur di RSUD Andi Makkasau Kota Parepare di Ruang Output(Bagian Distribusi) dengan waktu 15 menit pada inkubasi 24-48 jam. Pada Tabel 3 menunjukkan bahwa angka kuman lantai ruang dapur di RSUD Andi Makkasau Kota Parepare di ruangan output (bagian distribusi). Di perhitungan pertama dengan lama inkubasi 24 jam jumlah kuman yang di hasilkan dengan pengukuran laboratorium dengan media petrifilm sebelum perlakuan sebanyak $825 \mathrm{CFU} / \mathrm{cm}^{2}$, sedangkan jumlah kuman menjadi $412 \mathrm{CFU} / \mathrm{cm}^{2}$ setelah perlakuan dengan pengepelan dengan penambahan desinfektan dengan kadar $20 \mathrm{ml}$. Pada perhitungan yang kedua dengan lama inkubasi 48 jam jumlah kuman baik itu sebelum perlakuan dan sesudah perlakuan dengan penambahan desinfektan sebanyak 20 $\mathrm{ml}$ mengalami sedikit peningkatan, di sebelum perlakuan dengan jumlah $825 \mathrm{CFU} / \mathrm{cm}^{2}$ menjadi $857 \mathrm{CFU} / \mathrm{cm}^{2}$, jadi peningkatan jumlah coloni sekitar $32 \mathrm{CFU} / \mathrm{cm}^{2}$. Begitu juga dengan jumlah kuman setelah perlakuan mengalami peningkatan dari $412 \mathrm{CFU} / \mathrm{cm}^{2}$ menjadi $435 \mathrm{CFU} / \mathrm{cm}^{2}$ ada juga peningkatan jumlah kuman sekitar $23 \mathrm{CFU} / \mathrm{cm}^{2}$. Jadi jumlah penurunan angka kuman sebelum dan sesudah perlakuan dengan penambahan desinfektan dengan kadar $20 \mathrm{ml}$ di ruang output ( bagian distribusi) yaitu pada perhitungan pertama penurunan jumlah kuman sekitar $413 \mathrm{CFU} / \mathrm{cm}^{2}$ dan penurunan jumlah kuman pada perhitungan kedua sekitar 422 $\mathrm{CFU} / \mathrm{cm}^{2}$.

\section{PEMBAHASAN}

Berdasarkan Keputusan Menteri kesehatan Republik Indonesia Nomor1204/Menkes/SK/X/2004 tentang Persyaratan kesehatan Lingkungn Rumah Sakit, Persyaratan angka kuman untuk lantai dapur untuk batas maksimum yaitu 500 $\mathrm{CFU} / \mathrm{cm}^{2}$. Dimana kreteria di katakan menemuhi syarat apabila jumlah kuman di $<500 \mathrm{CFU} / \mathrm{cm}^{2}$ dan tidak memenuhi syarat apabila jumlah kuman>500 $\mathrm{CFU} / \mathrm{cm}^{2}$. Pengukuran angka kuman lantai ruang dapur di RSUD Andi Makkasau Kota 
Parepare di ruang dapur dan presentase penurunan jumlah kuman. pada Tabel 4. Pada tabel 4 menunjukkan bahwa angka kuman pada lantai ruang dapur setelah penambahan desinfektan pada ruang bagian input,proses, dan output ada yang memenuhi kreteria dan ada yang tidak memenuhi kriteria, namun ada presentase penurunan jumlah angka kuman. Menurut Sugiyono (2012) memberikan statistik deskriptif untuk mencari presentase penurunan di peroleh dengan rumus sebagai berikut. ${ }^{4}$

\section{$\mathbf{P}=\{(\underline{\mathbf{R X}}) \times 100 \%\}$ RT}

Menurut Mitchael J Pelezar, Jr, et,. Al., (1988, h.488-489) untuk mencapai tujuan yang maksimal dalam pemilihan bahan desinfektan,faktor-faktor yang harus diperhatikan adalah. Kosentrasi dan intensitas zat antimicrobial yaitu Makin tinggi konsentrasi atau makin besar intensitas yang diberikan maka makin cepat sel-sel atau sasaran akan mati dan terbunuh.Jumlah mikroorganisme yaitu Diperlukan waktu yang lama untuk membunuh populasi. Bila jumlah selnya banyak maka perlakuan diberikan lebih lama supaya yakin bahwa sel tersebut akan mati. Suhu yaitu Kenaikkan suhu dapat mempercepat atau menaikkan keefektifan suatu desinfektan.

Spesies mikroorganisme yaitu Spesies mikroorganisme menunjukkan kerentanan yang berbeda -beda terhadap tempat dan bahan kimia. Adanya bahan mikroorganisme lain yaitu Adanya bahan organik asing dapat menurunkan keefektifan zat kimia dengan cara menonaktifkan bahan bahan tersebut atau melindungi mikroorganisme. $p H$ yaitu Mikroorganisme yang terdapat pada bahan dengan $\mathrm{pH}$ asam dapat dibasmi pada suhu yang lebih rendah dan dalam waktu singkat dibandingkan mikroorganisme yang sama di lingkungan $\mathrm{pH}$ basah.

Sifat bahan yang akn diberi perlakuan yaitu Desinfektan yang digunakan untuk perabotan yang terkontaminasi,maka tidak boleh kontak langsung dengan kulit. ${ }^{5}$

Mekanisme kerja desinfektan menurut Nyoman Suhendra, et. Al. (1992, h. 76 ), faktor utama yang menetukan bagaimana desinfektan bekerja adalah kadar desinfektan, waktu yang diberikan kepada desinfektan untuk bekerja, suhu desinfektan, jumlah dan tipe mikroorganisme yang ada dan keadaan bahan yang didesinfeksi. Apabila proses desinfeksi ditujukan pada patogen tertentu,agen yang dipilih sebagai desinfektan harus dikenal sebagai bakterisida efektif terhadap organisme tersebut. ${ }^{6}$

Jadi angka kuman pada lantai ruang dapur di RSUD Andi Makkasau Kota Parepare pada ruang bagian input dan ruang bagian proses tidak memenuhi syarat dan ruang bagian output memenuhi syarat tetapi ada presentase penurunan jumlah angka kuman. Dari hasil pengukuran angka kuman yang 
telah di lakukan di laboratorium ada beberapa potensi dan faktor ekternal yang mempengaruhi jumlah kuman baik sebelum dan sesudah perlakuan di antaranya:

\section{Suhu ruangan}

Menurut Kepmenkes RI No. 1204/Menkes/SK/X/2004 tentangpersyaratan kesehatan lingkungan rumah sakit, suhu di ruang dapur distandarkan $22-30^{\circ} \mathrm{C}$. Suhu terendaahbiasanya terjadi pada pagi hari, karena pada pagi hari intensitas sinar matahariyang masuk ke dalam ruangan. Suhu ruangan akan mengalami kenaikansedikit demi sedikit seiring dengan bertambahnya intensitas sinar matahariyang masuk ke daalamruangan. ${ }^{1}$

Spesies dari bakteri dapat tumbuh pada suhu $0^{\circ} \mathrm{C}$, sedangkan spesies yang lainnya adayang tumbuh pada suhu yang ekstrim yaitu $90^{\circ} \mathrm{C}$ atau lebih. Pada umumnya bakteri tumbuh pada batas kedua batas ekstrim tersebut $\left(0-90^{\circ} \mathrm{C}\right)$. Usaha untuk menurunkan suhu ruangan dapat dilakukan dengan jalanmengupayakan pemanfaatan penghawaan alami secara optimum, artinya padaruangan yang jendelanya permanen di usahakan dibuat tidak permanen dan pengaturan jumlah pengunjung dan jam kunjungan, pengaturan jumlahpenunggu pasien yang ada di ruangan, sosialisasi tata tertib ruangan denganmenempelkan tata tertib pada tiap ruangan. Kelancaran sirkulasi udara didalam ruangan diharapkan dapat mengkondisikan ruangan sesuai dengan persyaratan sehingga angka kuman tetap rendah, karena secara tidak langsung suhu dapat mempengaruhi jumlah kuman lantai.

Kelembaban Ruangan Menurut Kepmenkes RI No 1204/ tahun 2009 tentang persyaratan kesehatan lingkungan rumah sakit, kelembaban di ruang dapur distandarkan 35 60\%. Menurut Depkes RI (1996, h.23) udara ruang yang terlalu lembab dapat menyebabkan tumbuhnya bermacam-macam jamur dan spora. Udara yang terlalu kering menyebabkan keringnya lapisan mukosa dan merupakan predisposisi infeksi saluran pernapasan akut. Kelembaban ruangan dapat berpengaruh terhadap mikroorganisme yang ada di lantai, tetapi mikroorganisme tersebut dapat hidup dan berkembang tidak hanya tergantung kepada kelembaban ruangan saja, tetapi lebih membutuhkan unsur - unsur yang lain. Pencahayaan Ruangan

Sesuai

Kepmenkes

RI

No.1204/menkes/SK/2004 tentang persyaratan kesehatan lingkungan rumah sakit, standar pencahayaan untuk ruang dapur yaitu minimal 200 lux. Kebisingan sesuai Kepmenkes RI No.1204/menkes/SK/2004 tentang persyaratan kesehatan lingkungan rumah sakit, standar kebisingan untuk ruang dapur yaitu $78 \mathrm{dBA} .^{7}$

Dari uraian di atas dapat kita simpulkan bahwa suhu ruangan,kelembaban ruangan, pencahayaan ruangan, dan kebisingan itu bukan faktor utama yang mempengahui penurunan jumlah kuman, melainkan kadar desinfektanlah yang 
mempengaruhi jumlah penurunan angka kuman,semakin banyak kadar desinfektan maka semakin tinggi jumlah penurunan angka kuman.

\section{KESIMPULAN DAN SARAN}

Berdasarkan hasil penelitian yang di lakukan di RSUD Andi Makkasau Kota Pare dengan uji laboratorium di UPTD Lumpue, dapat di tarik kesimpulan yaitu Kondisi sanitasi lantai ruang dapur di RSUD Andi Makkasau Kota Parepare tidak memenuhi syarat sebelum penambahan desinfektan, untuk ruang bagian penyimpanan jumlah kuman 1260-1284 CFU/cm ${ }^{2}$, ruang bagian pengelolaan jumlah kuman 1175-1201 $\mathrm{CFU} / \mathrm{cm}^{2}$, dan ruang bagian distribusi jumlah kuman 825-875 CFU/cm² (untuk lebih jelasnya lihat tabel 4), Angka kuman pada lantai ruang dapur di RSUD Andi Makkasau Kota Parepare ada yang memenuhi syarat yaitu ruang bagian distribusi dengan jumlah kuman 412-435 CFU/ $\mathrm{cm}^{2}$, dan ada yang tidak memenuhi syarat yaitu ruang bagian input dengan jumlah kuman 590-607 CFU/ $\mathrm{cm}^{2}$ dan ruang bagian proses dengan jumlah kuman 554-583 CFU/cm ${ }^{2}$ setelah penambahan kadar desinfektan serta ada presentase penurunan angka kuman (lihat tabel 4), dan jumlah angka kuman pada lantai ruang dapur di RSUD Andi Makkasau Kota Parepare ada yang memenuhi syarat dan ada yang tidak memenuhi syarat serta ada perbedaan dalam penurunan angka kuman setelah penambahan kadar desinfektan sebanyak $40 \mathrm{ml}$ dengan presentase penurunan $52,90 \%, 30 \mathrm{ml}$ dengan presentase penurunan $52,10 \%$, dan $20 \mathrm{ml}$ presentase penurunan 49,64\% /3 liter air (lihat Tabel 4).

Sebaiknya untuk pihak rumah sakit agar meningkatkan peran dan kinerja petugas dalam upaya peningkatan kebersihan lingkungan rumah sakit, khusus pada kebersihan lantai ruang dapur dengan seminimal mungkin di lakukan 2 kali pengepelan setiap hari dengan memperhatikan jenis dan kadar desinfektan yang digunakan, Bagi peneliti yang telah melakukan penelitian tentang analisis kondisi sanitasi lantai ruang dapur terhadap jumlah angka kuman RSUD Andi Makkasau Kota Parepare di jadikan sebagai pengetahuan untuk masuk di dunia kerja, dan Dan untuk peneliti berikutnya yang akan melakukan penelitian dengan judul yang sama atau memiliki keterkaitan dan rancangan yang sama supaya di jadikan sebagai sumber referensi. 


\section{DAFTAR PUSTAKA}

1. Indonesia, Departemen Kesehatan. Keputusan Menteri Kesehatan Republik Indonesia Nomor 1204/Me nkes/ SK/X/2004 Tentang Persyaratan Kesehatan Lingkungan Rumah Sakit, Jakarta, Direktorat jenderal pemberantasan Penyakit Menukar dan Penyakit Lingkungan; 2004.

2. Suendra.N . Pengaruh Dosis Desinfektan terhadap Penurunan Angka Kuman di Lantai. Purwakerto et. Al. (1993, h. 33); 1993.

3. Sugiyono.. Persentase penurunan. Bandung: Alfabeta; 2012.
4. Pelezar, M.J. Dasar-dasar Mikrobiologi. Jr, et,. Al., (1988, h.488-489). Jakarta; 2004.

5. Suhendra.,N. Mekanisme Kerja Desinfektan, et. Al. (1992, h. 76 ); 1992.

6. Teguh Sumito. Kajian Suhu, Kelembaban dan Pencahayaan Kaitannya dengan Jumlah Kuman Udara di Ruang BBRT dan ICU Rumah Sakit Dr.Kariadi. Universitas Diponegoro; 2007.

7. Usman, Lilis Suriani. Pengembangan Sistem Edukasi Pencegahan Penyakit Diare Berbasis Development of Civil Society di Kota Pare-Pare. VISIKES "Jurnal Kesehatan Masyarakat" 2016; 15(2): 79-89. 


\section{LAMPIRAN}

Tabel 1. Pengukuran Angka Kuman Lantai Ruang Dapur di RSUD Andi Makkasau Kota Parepare di Ruang Input(Bagian Penyimpanan) dengan waktu 15 menit pada inkubasi 24-48 jam

\begin{tabular}{ccccc}
\hline No & $\begin{array}{c}\text { Kadar Desinfektan } \\
(\text { ml/Liter air) }\end{array}$ & $\begin{array}{c}\text { Jumlah } \\
\text { Mikroorganisme } \\
\text { Perhitungan 1 }\end{array}$ & $\begin{array}{c}\text { Jumlah } \\
\text { Mikroorganisme } \\
\text { Perhitungan 2 }\end{array}$ & $\begin{array}{c}\text { Jumlah } \\
\text { Peningkatan } \\
\text { Mikroorganisme }\end{array}$ \\
\hline 1. & Sebelum Perlakuan & 1260 & 1284 & 24 \\
\hline 2. & $40 \mathrm{ml} / 3$ liter air & 590 & 607 & 17 \\
\hline $\begin{array}{c}\text { Jumlah Penurunan } \\
\text { Mikroorganisme }\end{array}$ & $\mathbf{6 7 0}$ & $\mathbf{6 7 7}$ & - \\
\hline
\end{tabular}

Sumber : Data Primer (2018).

Tabel 2. Pengukuran Angka Kuman pada titik 2 Lantai Ruang Dapur di RSUD Andi Makkasau Kota

Parepare di Ruang Proses (Bagian Pengelolaan) Dengan Waktu 15 Menit

Pada Inkubasi 24-48 Jam.

\begin{tabular}{ccccc}
\hline No & $\begin{array}{c}\text { Kadar Desinfektan } \\
(\mathbf{m l} / \text { Liter air) }\end{array}$ & $\begin{array}{c}\text { Jumlah } \\
\text { Mikroorganisme } \\
\text { Perhitungan 1 }\end{array}$ & $\begin{array}{c}\text { Jumlah } \\
\text { Mikroorganisme } \\
\text { Perhitungan 2 }\end{array}$ & $\begin{array}{c}\text { Jumlah } \\
\text { Peningkatan } \\
\text { Mikroorganisme }\end{array}$ \\
\hline 1. & Sebelum Perlakuan & 1175 & 1201 & 26 \\
\hline 2. & $30 \mathrm{ml} / 3$ liter air & 554 & 583 & 29 \\
\hline $\begin{array}{l}\text { Jumlah Penurunan } \\
\text { Mikroorganisme }\end{array}$ & $\mathbf{6 2 1}$ & $\mathbf{6 1 8}$ & - \\
\hline
\end{tabular}

Sumber : Data Primer (2018).

Tabel 3. Pengukuran Angka Kuman Lantai Ruang Dapur di RSUD Andi Makkasau Kota Parepare di Ruang Output(Bagian Distribusi) dengan waktu 15 menit pada inkubasi 24-48 jam

\begin{tabular}{ccccc}
\hline No & $\begin{array}{c}\text { Kadar } \\
\text { Desinfektan } \\
\text { (ml/Liter air) }\end{array}$ & $\begin{array}{c}\text { Jumlah } \\
\text { Mikroorganisme } \\
\text { Perhitungan 1 }\end{array}$ & $\begin{array}{c}\text { Jumlah } \\
\text { Mikroorganisme } \\
\text { Perhitungan 2 }\end{array}$ & $\begin{array}{c}\text { Jumlah } \\
\text { Peningkatan } \\
\text { Mikroorganisme }\end{array}$ \\
\hline 1. & Sebelum Perlakuan & 825 & 857 & 32 \\
\hline 2. & $20 \mathrm{ml} / 3$ liter air & 412 & 435 & 23 \\
\hline
\end{tabular}




\begin{tabular}{cccc}
$\begin{array}{c}\text { Jumlah Penurunan } \\
\text { Mikroorganisme }\end{array}$ & 413 & 422 & - \\
\hline
\end{tabular}

Sumber : Data Primer (2018).

Tabel 4. Pengukuran Angka Kuman Lantai Ruang Dapur di RSUD Andi Makkasau Kota Parepare di Ruang Dapur dan Presentase Penurunan Jumlah Kuman

\begin{tabular}{|c|c|c|c|c|c|c|c|c|}
\hline \multirow[t]{2}{*}{ No } & \multirow{2}{*}{$\begin{array}{l}\text { Kadar Desinfektan } \\
\text { (ml/liter) }\end{array}$} & \multicolumn{2}{|c|}{$\begin{array}{c}\text { Jumlah } \\
\text { Mikroorganisme }\end{array}$} & \multicolumn{2}{|c|}{ Penurunan } & \multicolumn{2}{|c|}{ Rata-rata } & \multirow{2}{*}{$\begin{array}{c}\text { Persentase } \\
\quad(\%)\end{array}$} \\
\hline & & T1 & $\mathbf{T 2}$ & X1 & $\mathrm{X} 2$ & RT & RX & \\
\hline 1 & $\begin{array}{l}\text { Sebelum perlakuan } \\
\text { di ruang input }\end{array}$ & 1260 & 1284 & \multirow{2}{*}{670} & \multirow[t]{2}{*}{677} & \multirow[t]{2}{*}{1272} & \multirow[t]{2}{*}{673.5} & \multirow[t]{2}{*}{$52,94 \%$} \\
\hline 2 & $40 \mathrm{ml}$ & 590 & 607 & & & & & \\
\hline 3 & $\begin{array}{l}\text { Sebelum perlakuan } \\
\text { di ruang proses }\end{array}$ & 1175 & 1201 & \multirow{2}{*}{621} & \multirow{2}{*}{618} & \multirow{2}{*}{1188} & \multirow{2}{*}{619.5} & \multirow{2}{*}{$52,14 \%$} \\
\hline 4 & $30 \mathrm{ml}$ & 554 & 583 & & & & & \\
\hline 5 & $\begin{array}{l}\text { Sebelum perlakuan } \\
\text { di ruang output }\end{array}$ & 825 & 857 & \multirow{2}{*}{413} & \multirow{2}{*}{422} & \multirow{2}{*}{841} & \multirow{2}{*}{417.5} & \multirow{2}{*}{$49,64 \%$} \\
\hline 6 & $20 \mathrm{ml}$ & 412 & 435 & & & & & \\
\hline
\end{tabular}

Sumber : Data Primer (2018). 